University of Wollongong

Research Online

Faculty of Social Sciences - Papers (Archive) Faculty of Arts, Social Sciences \& Humanities

$1-1-2018$

Joining the research conversation: threshold concepts embedded in the literature review

Meeta Chatterjee

University of Wollongong, meeta@uow.edu.au

Wendy S. Nielsen

University of Wollongong, wnielsen@uow.edu.au

Sarah Sanders

Villawood East Public School

Follow this and additional works at: https://ro.uow.edu.au/sspapers

Part of the Education Commons, and the Social and Behavioral Sciences Commons

Research Online is the open access institutional repository for the University of Wollongong. For further information contact the UOW Library: research-pubs@uow.edu.au 


\title{
Joining the research conversation: threshold concepts embedded in the literature review
}

\begin{abstract}
Doctoral education scholars associate doctoral learning with certain threshold concepts, many of which are embedded in the literature review. In considering this, we draw from a literary metaphor of 'joining the conversation' and report on a doctoral writing programme that blended elements of workshops, 'shut-upand-write' sessions and thesis writing circles in the Faculty of Social Sciences at an Australian university. Findings illustrate conceptual thresholds engendered in the literature review. Study participants reported growing awareness of: the need for a critical voice; the difference between descriptive and critical writing; and, different ways to conduct and structure the literature review. Further, these are capacities and skills that develop iteratively over the candidature. To join the research conversation, gaining an understanding of these aspects of the conceptual threshold is important and, as indicated here, writing programmes that explicitly support this learning are vital to the process of scholarly development.

\section{Disciplines \\ Education | Social and Behavioral Sciences}

\section{Publication Details}

Chatterjee-Padmanabhan, M., Nielsen, W. \& Sanders, S. (2019). Joining the research conversation: threshold concepts embedded in the literature review. Higher Education Research and Development, 38 (3), 494-507.
\end{abstract}




\section{Joining the Research Conversation: Threshold concepts embedded in the Literature Review}

Dr Meeta Chatterjee-Padmanabhan (corresponding author) Learning Development

University of Wollongong

Wollongong, NSW

meeta@uow.edu.au

A/Prof Wendy Nielsen

School of Education, Faculty of Social Sciences

University of Wollongong

Wollongong, NSW

wnielsen@uow.edu.au

Ms Sarah Sanders

Villawood East Public School

Lowana Street, Villawood, NSW

sarah.sanders11@det.nsw.edu.au

Doctoral education scholars associate doctoral learning with certain threshold concepts, many of which are embedded in the literature review. In considering this, we draw from a literary metaphor of 'joining the conversation' and report on a doctoral writing program that blended elements of workshops, 'shut-up-andwrite' sessions and thesis writing circles in the Faculty of Social Sciences at an Australian university. Findings illustrate conceptual thresholds engendered in the literature review. Study participants reported growing awareness of: the need for a critical voice; the difference between descriptive and critical writing; and, different ways to conduct and structure the literature review. Further, these are capacities and skills that develop iteratively over the candidature. To join the research conversation, gaining an understanding of these aspects of the conceptual threshold is important and, as indicated here, writing programs that explicitly support this learning are vital to the process of scholarly development.

Keywords: doctoral pedagogy, research conversation, threshold concepts, literature review, thesis writing workshop

\section{Introduction}

The literature review is among the first steps taken by doctoral students to join their disciplinary conversations. Boote and Beile (2015) argued that doing "[a] substantive, thorough, sophisticated literature review is a precondition for doing substantive, thorough, sophisticated research" (p. 3). However, pedagogic support for developing the 
literature review beyond the supervision arrangements is often limited. Doctoral scholars must develop a fairly complex and tacit skill set entailed in joining the disciplinary conversation. In Australia, few doctoral students take courses during doctoral candidature, which could be a place to build writing capacity. In our context, doctoral students typically rely on their supervisory team for support in writing, which is becoming less available as workloads increase and possibly, HDR students' needs are greater. Thus, in many instances across Australia, thesis writing workshops or groups (generic or discipline-specific) provide pedagogic support beyond formal supervision or coursework. The current research explores doctoral candidates' perspectives and experiences of a thesis writing workshop series focused on developing the knowledge, capacities and skills embedded in the literature review.

The present study grew from a partnership between a Head of Postgraduate Studies and a doctoral writing advisor. Both were keen to support the development of research writing that was not driven by a remedial or crisis model of intervention. The program was part thesis writing circle, part workshop and part 'shut-up-and-write' session designed to help doctoral students to prepare the literature review. We believe, with Aitchison and Lee (2006), that writing entails knowledge creation and not merely knowledge recording and the literature review is a specific place to articulate this knowledge. Lee and Aitchison (2009) further argue that writing remains "neglected as a central component of doctoral education" (p. 87), even as writing support from supervisors cannot be taken for granted because not all supervisors are able to teach research writing (Woodward-Kron, 2007) or see it as their role.

Additionally, we adopt a group approach to writing support to mitigate the inevitable isolation in doctoral studies. We are persuaded by Guerin (2014) and Kamler and Thomson (2014) that writing is a social practice involving writers and readers and therefore, felt the need to create "new spaces for dialogue, reciprocity, respect for difference and enriched peer relationship" (Kamler \& Thomson, 2014, p. 164). In facilitating the thesis writing workshops, we aimed to promote a range of skills that may have limited space for development in other areas in doctoral training and invited all doctoral students in the Faculty to participate.

In terms of pedagogic theory in doctoral education, Kiley (2009) and Kiley and Wisker (2009) outlined threshold concepts in doctoral learning. We find these conceptually appealing. With Wisker (2015), we agree that the literature review is a place where a number of conceptual thresholds are evident. Paré (2017) argues that 
joining scholarly conversations at the doctoral level is daunting and entails not only reporting on debates but taking a position and signalling affiliations, critiquing the work of others and developing an authoritative voice. The literature review is thus a place for important epistemological and ontological work to engage with the disciplinary field and position one's own research in it. Understanding the multiple voices that have, over time, shaped the knowledge base of the discipline is a critical part of being at the disciplinary frontier, which is a key expectation of doctoral students. We note an additional dimension of stepping into the knowledge domain as a novice scholar who is doing identity work (Kamler \& Thomson, 2014) as part of becoming a scholar. 'Identity work' is an elusive term that includes developing a greater awareness of being an author and writing at a standard befitting scholarship at the doctoral level. The standard could include recognising structural conventions, developing an authorial voice that signals disciplinary expertise and overall, projecting a confident scholarly identity.

Apart from evaluating the three-session thesis writing workshop, we aimed to find out whether and how participants developed skills for writing the literature review and how this helped them join their disciplinary conversations. The research is guided by the following question: How can thesis writing workshops support doctoral students to acquire the threshold concept of the literature review?

\section{Threshold Concepts}

We adopt the notion of threshold concepts of learning as developed by Meyer and Land (1986) who argued that mastering certain concepts marked distinctive learning, aspects of which represent 'portals' to the discipline or field of knowledge. In doctoral education, much learning can be marked as a threshold because it is distinctive. We adopt Meyer and Land's notions of learning for our work in doctoral education: learning is transformative because both views about learning and self-as-learner are changed in the process of scholarly development. The learning is integrative because sense is being made across the disparate aspects of activity in the doctoral program. And, because learning is not reversed or unlearnt, it is also irreversible. Threshold concepts are aspects of a whole and there is a specificity and relatedness among the concepts, hence the learning is bounded. And, after all, learning is challenging and thus, troublesome. Thresholds signal "the entrance into the transformational state of liminality" (Meyer \& Land, 2005, p. 380), which we expect is recognisable as individuals develop their 
thinking and talk about their work. However, the concepts are abstract and difficult to articulate specifically.

Applying the notion of threshold concepts to doctoral studies was initiated by Kiley (2009) and later, Kiley and Wisker (2009). In their research, they interviewed doctoral supervisors and identified six areas of the thesis where doctoral students demonstrate their development as scholars:

- $\quad$ argument/thesis as a concept;

- concept of theory;

- concept of framework;

- concept of knowledge creation;

- concept of analysis and interpretation; and,

- concept of research paradigms.

Developing these threshold concepts resemble 'rites of passage' that are core learning challenges (see Kiley \& Wisker, 2009), but these are broad notions that pervade doctoral work. In a recent study, and seemingly reinforcing Nicola-Richmond et al.'s (2018) critique of the concepts, Kiley (2017) juxtaposed the threshold concepts against the Australian Quality Framework (2010) and outlined others that had not been previously identified, such as research integrity. While alerted to these other threshold concepts as they are interpreted in doctoral education, to ground the current research, we adopt Wisker's (2015) view that the literature review provides evidence of acquisition of multiple threshold concepts.

\section{The Literature Review}

Many of the threshold concepts in doctoral education are integral to the literature review. This is the place where doctoral writers must situate their contribution to knowledge (concept of knowledge construction) in the wider context of established research (Wisker, 2015). It is also a place where doctoral writers demonstrate an understanding of theoretical perspectives (concept of theory and framework); how these drive research design (concept of research paradigm) and processes of evaluating previous studies (concept of analysis and interpretation); and, how these ground and provide justification for the conduct of proposed study (concept of argument/thesis). Further, doctoral students need both discrete and integrated understanding of these concepts for successful completion. 
The literature review (LR) is pivotal to the thesis and writing the literature review is an iterative, ongoing process that involves updating previous versions of the LR to either accommodate fresh research or to include significant studies overlooked earlier. Revising the LR is a research activity "masquerading as a foundational process" (Wisker, 2015, p. 73) and therefore can be troublesome for doctoral writers:

Writing in a good literature review is informative, argumentative, analytical and engages with theories and questions. It can evidence a level of conceptual threshold crossing because it is in the very struggles with articulation, with the understanding expressed, that the author can show they have something to say about a breakthrough and a standpoint offered by their work, situated in ongoing conversations in the field. (Wisker, 2015, p. 68)

Wisker also notes the expectation that doctoral writers will develop a 'discoursal voice', which many find daunting and time-consuming (Kiley, 2009; Kiley \& Wisker, 2009).

Thus, the LR represents a unique challenge: "the difficulty of writing as an authority when one does not feel authoritative" (Kamler \& Thomson, 2008, p. 508). The LR is demanding because it performs many functions, according to Kamler and Thomson (2014), which include sketching out historical developments in the field; identifying the main debates; selecting studies that are most relevant to the proposed research; locating a gap in the literature; creating a warrant for the study; and identifying the contribution it will make to disciplinary knowledge. Developing these perspectives and then articulating them through each stage of candidature is work for every doctoral student. Confidence and skill development are part of this process too, although perhaps not as widely recognized.

The act of engaging with disciplinary voices and prior work in the field is essential to 'joining the conversation'. Nowhere is this more apparent in doctoral work than in the literature review according to Wisker (2015). Joining a research conversation is like attending a gathering of like-minded peers at a parlour gathering:

Imagine that you enter a parlour. You come late. When you arrive, others have long preceded you, and they are engaged in a heated discussion, a discussion too heated for them to pause and tell you exactly what it is about. In fact, the discussion had already begun long before any of them got there, so that no one present is qualified to retrace for you all the steps that had gone before. You listen 
for a while, until you decide that you have caught the tenor of the argument; then you put in your oar. Someone answers; you answer him; another comes to your defence; another aligns himself against you, to either the embarrassment or gratification of your opponent, depending upon the quality of your ally's assistance. However, the discussion is interminable. The hour grows late, you must depart. And you do depart, with the discussion still vigorously in progress. (Burke, 1973, cited in Horne, 2011, p. 237)

The parlour metaphor signals at least three key elements of disciplinary conversations that are 'vigorously in progress' for a new scholar: (1) making sense of the 'heated discussion' already in progress in the field of study; (2) independently gaining an understanding of the 'tenor of the argument' among the controversies or debates in the field; and, (3) developing a position from which to speak and metaphorically 'put in your oar'. Speaking then involves aligning with and defending the position against other speakers in 'interminable' disciplinary discussions.

We consider this the essence of developing doctoral scholarship and agree with Wisker (2015) that doctoral scholars need help to join 'the research conversation' constituted by the literature review. Drawing on Bakhtin's (1986) theory of dialogism, Wisker suggests that "entering the dialogue, the conversation, in the literature requires commitment, thoroughness and confidence to identify the discoursal voice and your own voice and feel you have a right to speak" (p. 65). Wisker points out that the steps are fraught with difficulty and, we see them as parallel to the stages of the parlour metaphor: (1) thoroughly scouring the literature; (2) gaining awareness of the genres so as to develop an acceptable tenor; and importantly, (3) developing confidence in one's right to speak. These are vital steps in entering the dialogue in a disciplinary community.

Responding to doctoral candidates' need for additional support to both enter the dialogue of the disciplinary community and develop appropriate writing skills, we developed a thesis writing workshop aiming to provide both pedagogic intervention and social space for doctoral writers (Li \& Vandermensbrugge, 2011; Mantai, 2015). The three-session series was a social space for mutual support, enhanced confidence and a sense of belonging to a scholarly community (Guerin, 2014). Meeting as a group was thus a platform to develop metalanguage to discuss argumentation in the LR, including specific attention to the importance of synthesis and evaluation of sources and 
discussions on cohesion, grammar and lexis. Within the sessions, it was important to foster students' ability to give and take feedback on writing-in-progress, which represent important skills for thesis completion, future work in the academy and the increasing expectation to publish during candidature. In this thesis writing workshop, we claimed a space for doctoral study focused on the genre of the LR because it constitutes a challenging piece of work that iteratively develops across the candidature.

Built into the genre of the literature review are a number of threshold concepts that doctoral scholars such as Kiley (2009) and Wisker (2015) consider vital. A welldeveloped literature review needs to demonstrate a competent understanding of what constitutes an argument; synthesis and analysis; the concepts of theories, frameworks and paradigms; and above all the concept of knowledge creation that follows distinctive disciplinary conventions. The workshop series as a form of engagement interlaced rich discussion on these elements and provided opportunities to rehearse them with peers as a possible way of demystifying the concepts that mark distinctive and transformational learning for doctoral writers.

\section{Study Context, Participants and Method}

This is a qualitative research study that explored how a thesis writing workshop helped doctoral students to approach the conceptual threshold of the literature review. We gathered student perspectives on their participation in the workshop series with the aim to evaluate how and in what ways their skills and confidence to produce the LR had been supported. The workshop series included mini-workshops, activities and discussions devoted to advancing understanding and developing skill in conducting the LR and critical capabilities to evaluate their own work. To trigger learning conversations between participants in the thesis writing sessions, texts that exemplified descriptive 'shopping list' varieties of literature reviews as well as analytical and critical literature reviews were presented to participants so they could discuss differences among the texts. Guidelines for giving and receiving feedback were provided as well as modelled.

We conducted the workshop over three 3.5-hour sessions for doctoral candidates in the Faculty of Social Sciences over a two-week period in late 2016. Activities are summarized in Figure 1. We purposefully invited candidates at any stage of candidature 


\begin{tabular}{|c|c|c|c|}
\hline & Session 1 & Session 2 & Session 3 \\
\hline Focus & $\begin{array}{l}\text { The Literature Review: } \\
\text { Conceptual thresholds. } \\
\text { Structuring a LR. }\end{array}$ & $\begin{array}{l}\text { Working with } \\
\text { feedback. } \\
\text { Doctoral writing as } \\
\text { identity work. } \\
\text { Critiquing and voice in } \\
\text { writing. }\end{array}$ & $\begin{array}{l}\text { Giving and receiving } \\
\text { feedback. }\end{array}$ \\
\hline Date of Session & Nov 29, 2016 & Dec 5, 2016 & Dec 8, 2016 \\
\hline Key activities & $\begin{array}{l}\text { Locating the LR. } \\
\text { LR as a genre. } \\
\text { Critical appraisal. } \\
\text { Doctoral thresholds. }\end{array}$ & $\begin{array}{l}\text { Quiet writing time. } \\
\text { Types of feedback. } \\
\text { Telling the research } \\
\text { story. }\end{array}$ & $\begin{array}{l}\text { Quiet writing time. } \\
\text { Feedback on drafts. } \\
\text { Tools for writing the } \\
\text { LR. }\end{array}$ \\
\hline
\end{tabular}

Figure 1. Key activities for the thesis writing workshop sessions

to attend the workshops believing that the work of the LR happens throughout the candidature and that both domestic and international students in our Faculty could benefit from additional supports, even as their individual needs likely differed. As a result, there were three students who had not yet presented their research proposals, while two students were in the final writing-up stages. The remaining nine participants were scattered across years 1-4 of their programs. Some of the 13 participating doctoral candidates were under the supervision of one or the other of the authors and 12 of the workshop participants volunteered for the research.

\section{Data gathering}

As doctoral educators, our approaches to researching our pedagogies include elements of action learning (Aubusson, Ewing \& Hoban, 2009), participant observation (Brockmann, 2011) and evaluation research. All doctoral candidates who attended the workshops were invited to join the research by participating in an individual semistructured interview, conducted by Author 3 (who was not involved in the workshops). The 30-minute interviews explored their experiences and perspectives about the workshops and included such questions as: What were your personal goals for attending the workshops? What aspects of the workshops did you find particularly helpful? How has your understanding of the literature review improved? The interviews were transcribed verbatim. 


\section{Analysis}

Data sources for this research include: interview transcripts; workshop planning documents; field notes from the workshops; and debriefing notes following each session. In a form of open coding, the three researchers independently conducted a thematic analysis of the interviews and subsequently met to share their respective analyses, which were discussed in terms of a priori categories from Kiley and Wisker (2009) on threshold concepts in doctoral education alongside candidates' perspectives on their processes of engaging with the LR portion of the thesis work. We further reviewed the workshop planning documents, field notes and debriefing notes and used these to refine our analytic categories and initial interpretations. Following this, we added a layer to our analysis of the data corpus to include the two metaphors: arriving late to a 'parlour conversation' and 'joining the research conversation'.

\section{Results}

Participants in the workshop series were guided to think specifically about the literature review as a genre of writing that has particular purpose and organisation in the thesis, and as part of a coherent whole. Workshop promotion materials made explicit the focus on the LR, thus, participants attended presumably because they identified their own learning needs and sought to build their capacities for producing the LR, which we interpret through a thematic analysis of student perspectives on workshop participation. Two broad categories of perspectives were generated. The first relates to understandings about the LR as a text type: the structure, the type and scope that represent disciplinary protocols of joining the research conversation. The other relates to the experience of the writing workshop and how it helped participants join the research conversation. These two categories represent aspects of participants' experiences of the workshop series but also develop the LR as a threshold concept reflecting particular kinds of supports that participants found helpful.

\section{Understanding the threshold concepts in writing the literature review}

In this section, we describe participants' growing awareness about the LR as both genre and process. We primarily draw from interviews with participating doctoral candidates in this analysis. When asked how their understanding of the LR had improved, 
participants articulated how they were shaping the review and the strategies they were developing to do so. For example, Marissa, a $5^{\text {th }}$ year PhD student, noted:

I think it really crystallised all the things I knew about literature reviews. I think my knowledge of this writing was a little segmented in that I had isolated knowledge of the purpose and general writing strategies for the literature review, but the workshops really connected everything to not only show how a literature review is a cohesive whole, but also how it relates to and informs the rest of the thesis.

Overall, Marissa's comment reflects on her earlier 'segmented' understanding and is beginning to see how to connect the pieces. We see this realisation as indicating her moving through a liminal space (Keefer, 2015) from 'isolated knowledge' to a more comprehensive awareness of the LR as a part of a whole, in a way, an integrated understanding of the threshold concept. This is an important advance for any developing scholar because the LR is both a specific text and a thesis chapter. We attribute this developing awareness to the workshop emphasis structuring the LR. Awareness of the purpose of the LR is part of the necessary knowledge to produce the LR, but to begin to see it as part of a cohesive whole perhaps indicates a readiness to join the conversation in one's field. As a fifth year student, it had taken Marissa a long time to come to this realisation, but her comments indicate an important shift in her thinking.

Participants who were earlier in their programs also showed signs indicating awareness of the need to connect the LR to other parts of the thesis. Katie was in her first year of study and her awareness was evident in a comment about how she felt the workshops were helpful: "it was more useful to plan what to write and important issues to explain to make good emphasis and why it is important to do this research." She particularly stressed that she now had a clearer understanding of the need to provide a rationale for her study. Her comments came in response to a quiet writing activity in the second workshop when students were asked to choose among a list of question prompts and write for 20 minutes. The choice of prompts included: What is your research question? What was/is your search strategy? Have separate themes emerged? Can they be integrated? Are there gaps? What is your stance? Writing pieces were then circulated in a 'jigsaw' type activity during a guided peer review session. As a first-year international student, Katie made links between issues in the literature and the significance of her study. In terms of the threshold concepts, we see this growing awareness about the structure of the LR and the connections needed across parts of the 
thesis as signalling the concept of analysis and interpretation so that the parts of the thesis fit together.

Another workshop activity reviewed how to conduct a LR. Daisy, who had just completed data gathering for her thesis, recognized that there are different ways to structure the LR:

some of the group had just done a little presentation on doing a systematic review...but then I thought, 'What am I doing? And what is the process of doing that?' If I am not doing a systematic review, then what am I doing?

This realisation helped Daisy to focus her thinking on her own writing. In noticing that there are different types of literature reviews, she began to reflect on the purpose, structure and staging of her own, drawing on the threshold concepts of analysis and interpretation and thesis as argument.

Structuring the LR raises questions about the scope of the review amidst the wider field. For example, Maria was overwhelmed by the volume of literature in her field and realised the need to be more selective about what to include in her literature review, which was a turning point for her writing:

I think my problem is, I was describing the literature review and I ended up with this massive reference list that was vaguely related to the area that I was looking at - and there has been a lot that has been written on it. I think just honing down on the important works and really doing a proper critique of the main writing is something that I really learnt.

Maria refers to decisions made in the process of the LR related to selecting dominant voices or important works in the field, also drawing from the threshold concept of analysis and interpretation. Of course, this is related to the research focus for her study, which is how the process of the LR should work iteratively to sharpen the focus of the thesis work. Maria is also starting to recognise the importance of her own voice in critiquing the literature. Doing 'a proper critique' may be daunting, but is necessary at the doctoral level and seems to signal an important facet of joining the research conversation. Maria, Katie and Marissa were at different points of their thesis work, but all benefitted from the range of workshop activities, that had multiple entry points, so that individuals could identify and work on their own learning needs. From their participation, we could also understand their needs better and adapt subsequent sessions 
to better target individual and collective learning needs, in some cases providing additional review activities or different discussion points. Further, depending on the student's stage of candidature, working specifically on structuring the LR supported them to develop the threshold concept of analysis and interpretation, in particular, for working within the disciplinary discourse in the field.

An additional workshop activity targeted the issue of being critical in reviewing literature. Frank found this activity helpful as he noted during the interview: "Some of the technical stuff presented in the screen by Dr M; it was useful, especially vocabulary. The other things that need to be noticed [that] I may have overlooked before....the main thing is the critical review." Frank is commenting on Session 2 workshop activities where, as a group, we generated a list of words or phrases indicating author commentary or critique pulled from the LR section of a selection of published articles. For example, the list included terms and phrases such as "it appears that", "the equivocal nature of the findings" and "there is a growing and lively body of literature". Explicitly pointing to where the author made a comment about the research or how it shapes the study being reported helps to sharpen doctoral students' skills in both recognising the critical voice and helping them to build critique into their writing and gaining additional experience with the concept of analysis and interpretation. This growing awareness suggests these doctoral students are coming to understand aspects of the threshold concept of the LR and taking steps to develop a unique voice that also communicates their ideas. In doctoral pedagogy, it is important to teach doctoral students to critique the research of others, which in turn helps them to build a critical lens on their own writing. Activities that explicitly analyse, interpret or evaluate the literature enable and support students to notice how critique is conducted in their disciplines and thus realise how language is deployed, which in turn provides a model for their own work.

Such language use was highlighted in another workshop activity that looked at two paragraphs written in two different styles but including the same information: (1) annotated bibliography (e.g. descriptive) and (2) critical review of literature. Gaining awareness of the differences between descriptive and critical writing can be applied to one's own writing, as Richard noted:

I am starting to think more critically because before [the workshop] I was.... a bit too descriptive. I have to come back and condense it and critique it, not just describe, 'Oh, someone said this and someone said this'. You need to critique it and make a contrast 
or comparison or something. Yeah. Make it more like a good piece of writing.

Richard had advanced to his third year of study and may have had much writing practice, but still gained new awareness about how to further develop his critical writing skill through focused workshop attention on key differences between descriptive and critical writing.

Most doctoral students need time and opportunity to develop writing skill that builds from descriptive to more critical writing. Channelling Wisker (2015) on the literature review, developing writing skill is also iterative and foundational. We heard from participants who had received feedback from their supervisors of the order: "this is descriptive -please analyse critically". Many doctoral students struggle to decode such an injunction. However, recognising the implicit difference between descriptive and critical writing is an important step toward appropriately responding to the feedback.

To further support students to work with supervisor commentary, and as a partial response to student feedback from Session 1, we added a peer review activity in Session 2. Daisy contributed a part of her LR for this activity. During the interview she commented:

I read over it before I handed it in and I thought, 'This is rubbish compared to what we spoke about in the first session. So, I looked at it and thought, 'That is inadequate. I still need to look at it.' In terms of the funnel, it was more so just jumping around everywhere. It is so condensed in terms of word count and so many concepts that I need to get in, that I was making points all over the place but never actually making an argument for them.

Daisy clearly recognises the need for a critical review of this work sample, but also the need for a structure to the argument. We see these realisations as important indicators of the thesis as argument threshold concept.

We had used a metaphor of a funnel as a way to consider an appropriate level of abstraction and how to build the argument through paragraphs and sections, e.g. more abstract early on growing tighter in focus as the paragraph or section develops and the argument builds. Daisy took up the metaphor in a meaningful way to critique her own writing and consider how to better structure her argument so as to reflect the metaphorical shape of the funnel. We also discussed other models for the LR such as Swales' (1990) Create a Research Space (CARS) model. This model describes moves in 
structuring a literature review that establish the territory, identify a niche or a gap in the literature, and then, occupy the space as a writer and scholar. These moves mirror both Wisker's (2015) early steps in joining the research conversation and entering a parlour conversation that is already under way. Importantly, we consider these steps or moves as indicators of acquiring the threshold concept of the literature review.

\section{Threshold concepts embedded in joining the conversation}

To this point, we have considered aspects of the threshold concepts enmeshed in the literature review. But, what signals a formal entry into the research conversation? In this section, we consider doctoral students' perspectives that we believe signal their acquisition of threshold concepts, which is a step toward active participation in a disciplinary community.

As in the parlour conversation metaphor adopted in this paper, speaking aloud about one's research can follow from an understanding of current dialogue in the field and developing something to say about it. However, being ready to talk about your work in a group setting such as a workshop with peers requires a degree of confidence and hence, we see this as a key signal of having joined the research conversation.

The workshops provided multiple opportunities for participants to talk about their work and then receive feedback, both from their peers and us as academic supporters. The group context for these activities is important, according to Frank:

I think that the level of confidence can be gained by this type of group interaction....So, mixing up with these people gives you a good empowerment in where you are and what you need to do. It is good for learning.

We modelled giving and receiving feedback and then asked participants to also do this in response to others talking about their writing. We found Frank's use of the term "empowerment" heartening. We aimed to encourage the development of an authorial voice, but this is an elusive and difficult concept to teach or rehearse and may only be a part of the threshold concept of argument/thesis in terms of the need to articulate and justify a position. The social space of the workshop sessions provided participating doctoral students an opportunity to reflect on their own research and rehearse a stance in front of a live audience, who reacted and provided feedback. Sarah confirmed the benefit of speaking aloud:

I was a little bit hesitant to talk about it at first. But I think if I tell people about this 
anxiety feeling then they can give me some other feedback....I had this anxiety but I kept to myself. In the second workshop, I just felt like I really need to get this out. I need to know other people's thoughts about my research and what to do about it....I feel like the ability to get out of my shell and just be able to speak up and not be afraid was the highlight of the workshop.

Sarah was in her third year and still experienced anxiety when speaking about her research. We noted this hesitancy to speak out among many of the workshop participants, but Sarah's need to 'get this out' signals a new confidence in, firstly admitting it, and then, seeking feedback, for which she was ready by the second workshop. She also found sympathy from her colleagues, who had experienced similar anxieties. Like Sarah, many participants felt that opening their writing and thinking to scrutiny was risky, but also recognised value in giving and receiving feedback. As Maria noted: "you get so immersed in your own work, when you step back... and are looking at another person's work, you [can] see flaws but also where they have done things well”.

The perceived risk in sharing your work can be mitigated by a friendly environment. When asked if the workshop had any impact on his confidence, Nathan, who was an international student in his fourth year, said:

Yes, it is in a positive way. We know the organizers and I have many friends in the workshop....Some people have different backgrounds, but we know quite a lot about each other. Not about their research, but we see a lot of each other. I also had the chance to view my voice, to talk about our studies with people and commenting on people's work. I feel a lot more confident and interested in talking to people about my study.

While Nathan did not actually share a piece of writing, his readiness to speak about his research signals growing confidence in his own voice. He did, however, offer feedback to others and gained from listening to comments about colleagues' work:

I did give feedback and I listened to other feedback that they gave to each other. I thought it was a good discussion to evaluate other people's work, the ways they are commenting on other people's work. I learn from the way that my friends wrote their literature review, cite their studies and identify gaps. 
We were surprised at what participants had learned by listening to each other: some seemed to find their own voices. Listening to how others respond to each other in conversation about research also helps those who are less confident understand the genre of the dialogue and is a step toward joining the conversation. This enables doctoral students at any stage of candidature to learn about the nature of critique and how to find one's voice, which are important benefits from the group format of the thesis writing workshop series and important aspects of the threshold concepts pertinent to the literature review. Of course, there are other places where developing scholars can get feedback, including from supervisors or at conferences. From our experiences with this workshop, we see value in encouraging sharing among participants in a friendly environment to understand the process of peer review and gain additional viewpoints on their work, but also to practice important scholarly skills in speaking out loud about research. And with the on-going nature of literature review work, these represent multiple opportunities to 'put an oar in'.

\section{Discussion}

We see developing writing skill through the process of conducting the literature review as an important skill set underlying all of Wisker's (2015) threshold concepts in doctoral education. Writing at a suitably scholarly level is implicated in communicating the research contribution (concept of knowledge construction); situating the research theoretically and methodologically (concepts of theory and framework and research paradigm); articulating analyses and making interpretations (concept of analysis and interpretation) ; and building the argument through the thesis (concept of argument/thesis).

In the pedagogic space of the thesis writing workshops, we were keen to foster doctoral learning that emphasised threshold concepts or core learning points that need to be demonstrated in a literature review. We acknowledge with Nicola-Richmond and colleagues (2018) that the literature on threshold concepts in doctoral work is still emerging and tools to measure them are not yet available. However, the qualitative responses that our participants provided indicated that they were gaining increasing confidence in conducting and writing the literature review. Participants had multiple opportunities to write about and discuss how their work contributes to knowledge in their fields. The concept of analysis and interpretation was discussed in the context of the distinction between description and critique in reviewing previous studies. Some of 
these elements could be considered 'developmental', however, we argue that these are aspects of joining the research conversation and doctoral work as a whole, and because these are developmental, they are not achieved in an either/or fashion. Some students may not have been ready to share their work publicly, which suggests they are still working to acquire the threshold concept. It could also mean they do not yet understand the importance or necessity of developing an individual voice. Hence, workshop activities provided multiple entry points to encourage participation, in order to "put in your oar' and begin to join the research conversation.

Understanding the genre of the literature review sheds light on the purpose, type, structure, tone and tenor of conversations in the field. Thus, joining the research conversation involves raised awareness, new realisations and advances to thinking and skills, which are 'learning leaps' (Wisker, 2015) that we consider as signals of transformed and crystallised understandings applicable to doctoral scholarship.

\section{Conclusion}

In the present study, we sought to explore the path to joining research conversations in light of threshold concepts in doctoral work. The literature review positions the research in the wider field but should reflect the scholar's critical voice. Further, the literature review develops iteratively over the program and doctoral candidates can thus be explicitly guided to focus on the literature review as an on-going piece of work at any stage.

The research reported here is significant for doctoral educators seeking to support candidates outside the formal supervision or coursework structures. The thesis writing workshop described here focused doctoral student attention on the literature review, which as pedagogic space for doctoral scholars, helps to develop skills and confidence to join the research conversation.

\section{Acknowledgements}

We acknowledge and thank the doctoral candidates who came along to workshops and then gave us time for interviews and on-going conversations. Without their feedback, we would have an impoverished view of this pedagogic space in doctoral education.

\section{References}


Aitchison, C \& Lee, A. (2006) 'Researching Writing: Problems and pedagogies', Teaching in Higher Education, 11, (3) 265-278.

Aubusson, P., Ewing, R., \& Hoban, G. (2009). Action learning in schools: Reframing teachers' professional learning and development. London: Routledge.

Australian Qualifications Framework Council. (2013). Australian Qualifications Framework (2 $2^{\text {nd }}$ ed.). Adelaide, SA: Australian Qualifications Framework Council.

Bakhtin, M. (1986). Speech genres and other late essays. (V. W. McGee, Trans., and C. Emerson \& M. Holmquist, Eds.). Austin, TX: University of Texas.

Boote, D. N., \& Beile, P. (2015). Scholars before researchers: On the centrality of the dissertation literature review in research preparation. Educational Researcher, 34(6), 1-15.

Brockmann, M. (2011). Problematising short-term participant observation and multimethod ethnographic studies. Ethnography and Education, 6(2), 229-243.

Cotterall, S. (2011). Doctoral students writing: Where's the pedagogy? Teaching in Higher Education, 16(4), 413-425.

Guerin, C. (2014). The gift of writing groups: Critique, community and confidence. In C. Aitchison \& C. Guerin (Eds.), Writing groups for doctoral education and beyond: Innovations in practice and theory (pp. 128-141). London: Routledge.

Horne, M. (2011). Writing into the knowledge society: A case of vulnerability in inkshedding. In D. Starke-Meyerring, A. Paré, N. Artemeva, M. Horne \& L. Yousoubova (Eds.), Writing in the knowledge society (pp. 237-256). Fort Collins, CO: The WAC Clearinghouse and Parlor Press.

Kamler, B., \& Thompson, P. (2008). The failure of dissertation advice books: Toward alternative pedagogies for doctoral writing. Educational Researcher, 37(8), 507-514.

Kamler, B., \& Thompson, P. (2014). Helping doctoral students write: Pedagogies for supervision. London: Routledge.

Keefer, J. (2015). Experiencing doctoral liminality as a conceptual threshold and how supervisors can use it. Innovations in Education and Teaching International, 52(1), 17-28, http://dx.doi.org/10.1080/14703297.2014.981839

Kiley, M. (2009). Identifying threshold concepts and proposing strategies to support doctoral candidates. Innovations in Education and Teaching International, 43(3), 293-304.

Kiley, M. (2017). An emerging PhD curriculum and what this might mean for doctoral level threshold concepts. Practice and Evidence of Scholarship of Teaching and Learning in Higher Education, 12(2), 294-312.

Kiley, M., \& Wisker, G. (2009). Threshold concepts in research education and evidence of threshold crossing. Higher Education Research and Development, 28, 431-441.

Lee, A., \& C. Aitchison. (2009). Writing for the doctorate and beyond. In D. Boud \& A. Lee (Eds.), Changing practices of doctoral education, (pp. 87-99). Oxon: Routledge.

Li, L. Y., \& Vandermensbrugge, J. (2011). Supporting the thesis writing process of international research students through an on-going writing group. Innovations in Education and Teaching International, 48(2), 195-205.

Mantai, L. (2015). Feeling like a researcher: Experiences of early doctoral students in Australia. Studies in Higher Education. Online 11 August, 2015. DOI: 10.1080/03075079.2015.1067603 
Meyer, J., \& Land, R. (Eds.) (2006). Overcoming barriers to student understanding: Threshold concepts and troublesome knowledge. Abington, UK: Routledge.

Nicola-Richmond, K., Pépin, G., Larkin, H., \& Taylor C. (2018). Threshold concepts in higher education: A synthesis of the literature relating to measurement of threshold crossing. Higher Education Research and Development, 37(1), 101114. DOI: $10.1080 / 07294360.2017 .1339181$

Paré, A. (2017). Re-thinking the dissertation and doctoral supervision/Reflexiones sobre la tesis doctoral y su supervisión. Journal for the Study of Education and Development, 40(3), 407-428. DOI: 10.1080/02103702.2017.1341102

Swales, J. (1990). Genre analysis: English in academic research settings. Cambridge: Cambridge University.

Wisker, G. (2015). Developing doctoral authors: Engaging with theoretical perspectives through literature review. Innovations in Education and Teaching International, 52(1), 64-74.

Woodward-Kron, R. (2007). Negotiating meanings and scaffolding learning: Writing support for non-English speaking background Postgraduate Students. Higher Education Research and Development, 26(3), 253-268. 